2018 Global Marketing Conference at Tokyo Proceedings: 1119-1129 (July 2018)

https://doi.org/10.15444/GMC2018.09.05.05

\title{
THE ROLE OF WORD-OF-MOUTH AND CELEBRITY ENDORSEMENT IN ONLINE CONSUMER-BRAND RELATIONSHIP: THE CONTEXT OF INSTAGRAM
}

\author{
Sandra Maria Correia Loureiro, Instituto Universitário de Lisboa (ISCTE-IUL), \\ Portugal $^{1}$ \\ Eduardo Moraes Sarmento, University Lusófona, Portugal ${ }^{2}$
}

\begin{abstract}
The aims of this study are to understand the influence of celebrity endorsement on consumers' word-of-mouth and decision behavior, that is: (i) understand the influence of the number of followers of the celebrity and the positive/negative valence of the messages conveyed by them in the intention to buy and their intention to generate eWoM; (ii) analyzing how the behavior of a celebrity (antisocial vs. pro-social) may affect the perception of its credibility, the intention of the consumers to relate to the celebrity in the social networks and the social identification with it; (iii) understand the impact of celebrity messages on brands and products present in social networks.

To achieve this goal a quantitative methodology for the development of research was adopted, selecting the application of a survey as the information collection instrument. The sample is selected by convenience sampling method, collecting 241 responses, 122 females and 119 males.

Findings show: (i) concerning the intention to purchase, female seem to be more influenced by the opinions and recommendations of celebrities, while male tend to be more likely to generate e-word-of-mouth into their contact network through social media. (ii) Regarding to antisocial versus prosocial type of celebrity, celebrities with a prosocial behavior seems to have a greater influence for both genders in the way they identify with celebrity and their willingness to relate to them. (iii) Female tends to feel higher purchase intention when exposed to an endorsement, where celebrity promotes a brand or product through its Instagram account.
\end{abstract}

Keywords: celebrity endorsement; social media; Instagram; electronic word-of-mouth.

\section{Introduction}

Celebrity endorsement is a common strategy for many brands that over the last few years have been using this powerful marketing tool as a way to communicate their products. A strategy that has become more and more relevant, particularly with the digital era and the growth of social networks. After the development of Web 2.0 and with the proliferation and importance of social networks -currently take on the day-today of consumers- the use of celebrities as part of a communication strategy has been extended to the digital environment.

Drefs (2016) states that celebrities as opinion leaders are vital as part of a marketing strategy, since sharing a brand's content on their personal page can generate six times more traffic and twice more conversions than in their absence. Senecal and Nantel (2004) argue that consumers are influenced in their choices of products online by

\footnotetext{
${ }^{1}$ sandramloureiro@netcabo.pt

2 emoraessarmento@gmail.com
} 
online recommendations. Consumers now have access to new sources of influence that can provide personalized product information and recommendations. Studies have shown that this type of information source influences consumers' choices in online products and is more influential than conventional referral sources. Marwick and Boyd (2011) argue that social networks allow consumers to connect by creating and sharing content, giving the example of using celebrity social networks, access to their "backstage". Celebrities share their personal lives to create a sense of intimacy and closeness between them and followers and use language and cultural references to build empathy with followers. The celebrities who are most involved in social networks may, therefore, facilitate and lead to a greater process of transferring celebrity aspirational values to the brand they promote and vice versa (Dwivedi et al., 2016).

The electronic word-of-mouth (eWOM) revolves around conversations about products and services among internet users (Hennig-Thurau et al., 2004) and social networks are appropriate platforms for such conversations. They provide an opportunity for people to share and exchange their opinions and experiences about brands with their friends on the Internet (Kozinets, de Valck, Wojnicki, \& Wilner, 2010). In addition, consumers increasingly rely on social networks to acquire information about brands they do not know very well (Naylor, Lamberton, \& West, 2012), because information given by friends and acquaintances is perceived as more credible and reliable (Chu \& Kim, 2011). EWOM can be understood as the "like", comments or sharing of "posts" of brands or celebrities visible to friends and other users and are valuable indicators of consumer engagement (Hoffman \& Fodor, 2010). When social network users like or follow a brand or celebrity, they get their updates and messages in their feed. Users can then "like", comment on, or share a "post" by spreading it through their friends' feed, whose interactions with the "post" will in turn make it retransmit their networks (Phua, Jin, \& Kim, 2017). Thus, ocial networks provide marketers with critical advantages in terms of word-of-mouth: first, marketers can interfere in conversations among consumers to avoid negative dialogues being spread worldwide; and secondly, they can lead consumers to engage in positive dialogues by providing consistent brand content (Erkan, 2015).

In this context, the main aims of the current study are: to understand the influence of celebrity endorsement on consumers' word-of-mouth and decision behavior, that is: (i) understand the influence of the number of followers of the celebrity and the positive/negative valence of the messages conveyed by them in the intention to buy and their intention to generate eWoM; (ii) analyzing how the behavior of a celebrity (antisocial vs. pro-social) may affect the perception of its credibility, the intention of the consumers to relate to the celebrity in the social networks and the social identification with it; (iii) understand the impact of celebrity messages on brands and products present in social networks.

\section{Theoretical backgroud}

The main difference between eWoM and traditional WoM is the platform in which consumers exchange information. Although it can be considered less personal, eWoM can (i) achieve a much larger scale and an unprecedented rate of diffusion (HennigThurau et al., 2004); (ii); allow the exchange of communication among consumers (Cheung \& Lee, 2012), it is available on the various platforms where it is shared (Cheung \& Lee, 2012) and it generates a large scale of information sources; (iii) intensify the relationship between a communicator and a recipient as the strength of 
the links between communicators and eWoM recipients is generally weak (Chatterjee, 2001).

Globally, positive information or comments on eWoM motivates the purchase of a brand (Lee, Rodgers, \& Kim, 2009), while negative eWoM comments reduces purchase intent and inhibits other brand behaviors (Chiou \& Chang, 2003, Bansal, Harvir, \& Voyer, 2000, Baker, Donthu, \& Kumar, 2016, Lee, Park, \& Han, 2008). When it comes to an online environment, negative eWoM can deter potential customers from considering a specific product/brand, thereby harming its reputation and financial position (Pfeffer et al., 2014), as it is known that the negative information has generally more impact on the judgment of a brand than positive information (Xia \& Bechwati, 2008).

Social capital and celebrity endorsement

Past research has focused little attention on the effect of eWoM by opinion leaders such as celebrities (e.g., Lee, Park, \& Han 2008). As online commentaries that proliferate across platforms are increasingly able to influence consumer opinions about their buying intentions (Chatterjee, 2011), the opportunities to monetize the status of these personalities as opinion leaders are increasingly plentiful (Carr \& Hayes, 2014).

In this vein, social networks (e.g., Instagram) may be regarded as a form of social capital as resources created through people's social relationships can be vehicles to achieve favorable social outcomes. The social networks facilitate the contact and interactions among people creating opportunities to those who are influential within their social context (e.g., celebrities).

Therefore, the influence of eWoM on social networks may be even greater than the traditional WoM, since eWoM can reach a global audience that shares similar interests in relation to a product or brand more easily and quickly (Argyriou, 2012). The digital revolution has expanded and accelerated the concept of word-of-mouth to the point where it is no longer a one-on-one communication. Products are evaluated online and opinions are disseminated through social networks, and are subsequently shared by thousands of users (McKinsey, 2010).

In this new paradigm, influencers, and more specifically celebrities in social networks, are a powerful tool to be recognized. Brands can strategically celebrate contracts with the right celebrities to spark organic brand conversations and engage with their followers more directly and on a larger scale (AdWeek, 2015).

Nowadays, eWoM uses microblogging that uses social networks like Twitter, Facebook, Instagram, among others (Jansen et al., 2009). Microblogging is a form of communication in which users can describe subjects of common interest and express attitudes they are willing to share with others through short messages. Microblogging has a direct impact on eWoM communication because it allows consumers to share opinions and brand considerations anywhere for almost everyone who is "connected" (via the computer or smartphone) to a scale never before seen (Kim \& Ko, 2012). The speed and global reach of eWoM in Instagram, for example, gives brands a way to leverage the power of communication between consumers and their relationship with consumer. On the other hand, new long-term relationships are created between brands and consumers, increasing the value of the consumer (Kim \& Ko, 2012) and due to its effectiveness and eWoM speed, through microblogging eWoM communication can occur very close to the purchasing decision-making or even during the purchasing process, having significant implications for the success of brands, companies and products (Barton, 2006).

The role of eWoM on purchasing decision process 
Comments or reviews are one of the key areas that have emerged from social networks, generating great value for consumers and businesses (Nambisan, 2002), as consumers seem to rely on seemingly disinterested opinions from consumers outside their social network, looking for opinions about products and services through social networks (Jansen et al., 2009). Thus, the quality and quantity of information produced in consumer reviews influences purchase intention through increased trust (Do-Hyung, Jumin and Ingoo, 2007).

Trust and credibility are two other important keys (Han \& Windsor, 2011). Consumers who use the internet are influenced by others' online opinions only when written by a highly trusted source (López and Sicilia, 2014) that does not have to be an expert or someone close to them. When people perceive a source as reliable, eWoM will have a greater influence on decision making. In addition, the reliability, competence and attractiveness of the source in a message also have positive effects on the reposting of information in social networks, being available to even more consumers (Liu et al., 2012).

Electronic WoM is considered to be an effective source of information because communication involves an informal exchange of opinions between friends or acquaintances, this is considered to be an effective source of information. Consumers intend to seek information from others while deciding to purchase a product (Gildin, 2003).

Several studies have explored the behavioral consequences of eWoM and concluded that eWoM's influence on attitude toward a product and its intent to purchase (Christodoulides et al., 2012, Lee \& Youn, 2009), together with the desire to recommend a product (Sun et al., 2006) and how information shapes consumer expectations (Jalilvand et al., 2011, Hung e Li (2007).

Given the role of celebrity-generated brand messages in social network, the consumers' identification with celebrities, as well as the influence of e-WoM on purchase decisions, the current study uses two experiments to examine the valence (negative versus positive) of celebrity endorsement into the context of Instagram between male and female.

In this vein, we conducted experiments to explore the influence of celebrities' social network followers and the valence of celebrity-generated messages (positive versus negative brand message) on source credibility of celebrity (H1); the effect of celebrities' social network followers and the valence (positive versus negative brand message) on intentions to purchase (H2) and intention to spread e-wom (H3); the effect of celebrity type ((i.e., prosocial versus antisocial) on source credibility of celebrity (H4) and intention to build an online friendship (H5); and finally the direct effect of celebrity type on intention to build an online friendship (H6) and social identification (H7) in comparison with the indirect effect through social identification (acting as mediator).

Figure 1. Framework and Hypotheses 


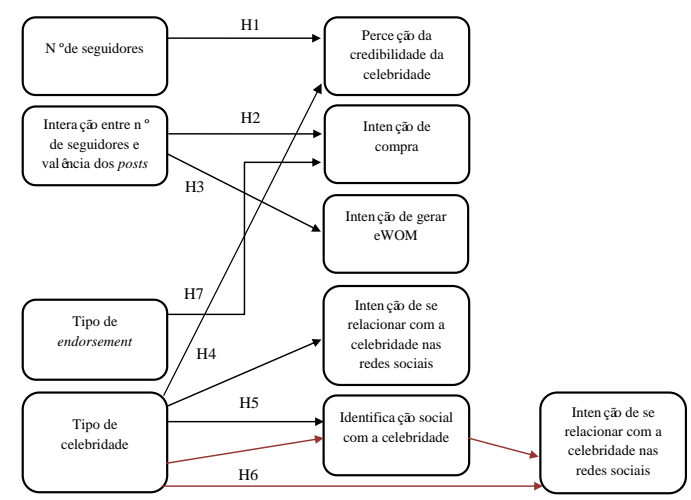

\section{Methodology}

The empirical research is conducted using a quantitative methodology, and a questionnaire survey was selected as the main instrument for collecting information. A sample composed of 122 female and 119 male. The process of data collection took place in August $(3-31,2017)$ using the Google Docs forms. In order to fill out the questionnaire, all participants had a user account on Instagram and a gender filter question was defined as a precondition to guide the respondent to the issues that were specific to him or her. The questionnaire consisted only of closed questions, using multiple choice questions and mainly Likert and semantic differential scales. Items and measurement scales used in the questionnaire were elaborated based on researches from other relevant authors in the scientific literature, already applied in other studies. The questionnaire used Instagram accounts of Portuguese celebrities through true "posts" in which celebrities recommended certain brands.

We developed three experiments:

(i) Experiment I aims to examine the effect of the number of followers on Instagram and the validity of the messages generated by the celebrities in the perception of their credibility, the intention to buy and the intention to generate eWOM by the respondents;

(ii) Experiment II, through the use of two articles exposed to the participants, one referring to a celebrity with antisocial behavior, another to a celebrity with a prosocial behavior, focused on the influence that positive or negative news about a Celebrity can have in the perception of their characteristics taking into account their social behavior and in the perception of their credibility, as well as in the intention of relating with it and in social identification;

(iii) Experiment III test if the type of endorsement (press announcement vs. "post" in Instagram) of a product influences the intention to buy, noticing if there were differences between the endorsements in the translation of results for the brand that was endorsed by the celebrity.

In all studies, products and brands presented to respondents are real and are recommended by the celebrities in their Instagram accounts. Only in experiment I due to the difficulty in finding "posts" in which the celebrities did not recommend a product or a brand- was necessary the use of messages to be included in the posts with negative valence, so that all the respondents could have access to "posts" in which celebrities did not recommend a product. In this study, we consider four manipulations for each condition (low number of followers vs. high number of followers), two distinct manipulations considering the valence of the messages.

\section{Conclusions and implications}

Table 1 presents a summary of the hypotheses.

Table 1 . Summary of the results 


\begin{tabular}{|l|l|l|}
\hline \multirow{2}{*}{ Hypothesis } & Sample & \\
\cline { 2 - 3 } & Female & Male \\
\hline H1 & Rejected & Partially accepted \\
\hline H2 & Partially accepted & Rejected \\
\hline H3 & Rejected & Partially accepted \\
\hline H4 & Accepted & Accepted \\
\hline H5 & Accepted & Accepted \\
\hline H6 & Accepted & Accepted \\
\hline H7 & Accepted & Rejected \\
\hline
\end{tabular}

These results allow us to suggest that:

- The number of followers that a celebrity has on their Instagram has no influence on their credibility for female consumers, revealing that the fact that a celebrity has more or less followers does not mean that their opinion or recommendations about products or brands more or less credible. For male consumers, however, only attractiveness, one of the dimensions that integrate credibility, is influenced by the number of followers so much that if a celebrity is more physically attractive their credibility increases. It should be noted, however, that since the other dimensions of credibility (reliability and competence) are not influenced by the number of followers, it cannot be concluded that this factor has a total influence on the credibility of the celebrity.

- The number of followers and the validity of messages about celebrity-delivered products on their Instagram are two interacting factors influencing the female consumers' purchase intent. That is, when a celebrity has few followers, exposure to negative messages about a brand or product nevertheless tends to increase their purchase intent, which may indicate that their opinion is not so valued. When this is a popular celebrity on Instagram, with many followers, the recommendation of a brand increases their purchase intention, valuing their recommendation. For male consumers, the interaction between these two factors has no bearing on their intent to buy, however when celebrity recommends some product, consumers tend to increase their intention to buy. Overall, a positive recommendation from a celebrity has a positive effect on the purchase intentions of consumers of both sexes.

- Male consumers are more influenced to generate eWOM, i.e., to share posts and messages with other consumers through their own social network, only to the recommendation of a brand by a celebrity with a high number of followers, something that does not occur before a positive recommendation or negative opinion shared by a celebrity with few followers, indicating here that the high number of followers is a factor to be taken into account and that consumers are more willing to share positive than negative messages when the celebrity has a greater following. Consumers are not influenced, by the interaction of these factors, to share messages in their social networks.

- The social behavior of a celebrity has an influence on the credibility perceived by consumers, both female and male, revealing that when the celebrity has a pro-social behavior (it seems to contribute positively to society, for the benefit of others and in an altruistic way) this is reflected in an increase in its credibility. On the contrary, when celebrity is seen to have negative or unethical behaviors its credibility decreases. Their social behavior is also reflected in the social identification that consumers feel with the celebrity and their intention to relate to it, in this case through social networks. Before a celebrity who has a pro-social behavior, consumers feel a greater identification and greater willingness to relate to the same, compared to a celebrity who has behavior considered inappropriate. In addition, the study also reveals that 
social identification has a mediating role in the relationship between celebrity behavior and the intention to relate to it, suggesting the importance of this factor when consumers are exposed to an advertisement to a brand or product made by an endorser. - In an endorsement situation where the celebrity promotes a brand or product through their Instagram account, female consumers feel more intent to buy than through an advertising campaign through a press announcement. This suggests that the type of endorsement is a factor that influences the consumers' intention to buy, indicating that the proximity and the ease with which the product is demonstrated in the celebrity social network make the recommendation have a greater impact. The same does not apply to male consumers who reveal they are no longer influenced in their intent to purchase for an endorsement through Celebrity Instagram.

The use of real celebrities as well as true "posts" and brand content (though only in relation to positive messages) was one of the innovative aspects of this study, as well as the distinction made between men and women, having been important in some distinctions in their behavior, bringing a different empirical approach. Another innovative and relevant aspect was to understand the greater effectiveness that an endorsement through the social network of a celebrity intends to purchase from the female consumers compared to a more traditional endorsement model, such as an advertising campaign in a press announcement.

The study confirms the influence of celebrity endorser as an effective tool for promoting brands in social networks particularly those who are seen as having a prosocial behavior, and the choice of endorser should be judiciously made considering this aspect. This should therefore be one of the main concerns for brands, since the desire to "follow" a celebrity depends to a large extent on the identification that consumers feel with it, as well as being considered as more credible. Through a segmentation of the sample between the masculine and feminine gender, this study may also prove interesting for the brands in the creation of strategies aimed at the male and female target audience through the perception of the differences of their behaviors.

As far as we know this is one of the first studies to address the issue of celebrity endorsement specifically for Instagram. The use of real celebrities as well as true "posts" and brand content (though only in relation to positive messages) was one of the innovative aspects of the study, as it was the distinction made between men and women. Another new and relevant aspect was to understand the greater effectiveness that an endorsement through a celebrity's social network intends to purchase from consumers compared to a more traditional endorsement model, such as an advertising campaign in a press announcement.

Regarding the implications for management, the study confirms the influence of celebrity endorser as an effective tool for promoting brands in social networks, particularly those who are seen as having a pro-social behavior, and the choice of endorser should be judiciously made taking into account this aspect. Therefore, this should be one of the main concerns for brands, since the desire to "follow" a celebrity depends to a large extent on the identification that consumers feel with it, as well as being considered as more credible. Through a segmentation of the sample between the masculine and feminine gender, this study may also prove to be interesting for the brands in the creation of strategies aimed at the male and female target audience, through the perception of the differences of their behaviors.

The limitations found in this study may be important suggestions for future research. One of the main limitations is the fact that the study sample was selected for convenience (a non-probabilistic sample). Future research should consider a random 
sampling method. Another limitation was that manipulations have been made using celebrity and "posts" with true brands. The fact that the respondents are already familiar with them may also have an adverse effect and constitute a limitation to the investigation. If participants have some negative opinion about a particular celebrity or brand, it can in a way influence and condition the respondents. In this way, it is suggested that an even more judicious pre-test should be done before choosing celebrities and brands to prevent these situations. The third limitations is the fact that Instagram is not yet a social network with as much expression in Portugal, as for example Facebook, and is still a growing platform which may make it impossible to formulate a precise conceptual model. The creation of other variables to be included in the study, such as widening the set of products to be used in manipulations or taking into account the impact that the age of the respondents may have on the influence of celebrity endorsement, besides gender, can also be a possible suggestion for future studies.

\section{References}

AdWeek. (2015). How Celebrities With the Best Instagram Engagement Are Helping Brands. $\quad$ http://www.adweek.com/news/technology/how-celebrities-bestinstagram-engagement-are-helping-brands-167922

Ambroise, L., Pantin-Sohier, G., Valette-florence, P., \& Albert, N. (2014). From endorsement to celebrity co-branding: Personality transfer. Journal of Brand Management. 21(4), 273-285.

Assael, H. (1992). Consumer behavior and marketing action. Boston: PWS-Kent.

Atkin, C. \& Block, M. (1983). Effectiveness of Celebrity Endorsers. Journal of Advertising Research. 23 (February/ March), 57-61.

Bansal, Harvir S. \& Voyer, Peter A. 2000. Word-of-Mouth Processes Within a Services Purchase Decision Context. Journal of Service Research, 3(2), 166177.

Baker, A. M., Donthu, N., \& Kumar, V. (2016). Investigating how word-of-mouth conversations about brands influence purchase and retransmission intentions. Journal of Marketing Research. 53(2), 225-239

Barton, B. (2006). Ratings, reviews \& ROI: How leading retailers use customer word of mouth in marketing and merchandising. Journal of Advertising Research. $7(1), 1-7$.

Carr, C. T., \& Hayes, R. A. (2014). The Effect of Disclosure of Third-Party Influence on an Opinion Leader's Credibility and Electronic Word of Mouth in Two-Step Flow. Journal of Interactive Advertising. 14(1), 38-50.

Chatterjee, P. (2001). Online review: do consumers use them?. Advances in Consumer Research. 28,129-133

Chatterjee, P. (2011). Drivers of new product recommending and referral behaviour on social network sites. International Journal of Advertising. 30(1), 77-101.

Chen, Yubo; Fay, Scott; \& Wang, Qi (2011). The Role of Marketing in Social Media: How Online Consumer Reviews Evolve, Journal of Interactive Marketing. 25 (2): 85-94.

Cheung, K., \& Lee, O. (2012). What drives consumers to spread electronic word of mouth in online consumer-opinion platforms. Decision Support Systems. 53(1), 218-225

Cheung, C. M. K., \& Thadani, D. R. (2012). The impact of electronic word-ofmouthcommunication: A literature analysis and integrative model. Decision SupportSystems. 54(1), 461-470. 
Chia, C, \& Poo, L. (2009). Media, celebrities, and fans: An examination of adolescents' media usage and involvementwith entertainment celebrities. Journalism \& Mass Communication Quarterly. 86, 23-44.

Chiou, J.-S. \& Cheng, C. (2003). Should A Company Have Message Boards on Its Web Sites? Journal of Interactive Marketing, 17 (Summer): 50-61.

Argyriou, E.; Christodoulides, G. \& Michaelidou, N. (2012). Cross-national differences in e-WOM influence. European Journal of Marketing. 46(11), 1689-1707.

Chu, S., \& Kim, Y. (2011). Determinants of consumer engagement in electronic word-of-mouth (eWOM) in social networking sites. International Journal of Advertising. 30(1), 47-75

Do-Hyung, P., Lee, J., \& Han, I. (2007). The effect of on-line consumer reviews on consumer purchasing intention: The moderating role of involvement. International Journal of Electronic Commerce. 11(4). 125-148.

Drefs, M. (2016). Advocates, influencers and celebrities: your social media dictionary. http://www.oracle.com/oms/social-influencer/blog-matias-influence2212093.html. Accessed on 27.09.2016.

Dwivedi, A., Johnson, L., \& McDonald, R. (2016). Celebrity endorsements, selfbrand connection and relationship quality. International Journal of Advertising. 35(3), 486-503.

eMarketer. (2016). Consumers like reading online reviews not writing them. http://www.emarketer.com/Article/Consumers-Like-Reading-Online-ReviewsNot-Writing-Them/1014242. Accessed on 17.02.2016.

Erdogan, Z. Baker, M.; \& Tagg, S. (2001). Selecting Celebrity Endorsers: The Practitioner's Perspective. Journal of Advertising Research. 47 (3): 25-43.

Erkan, I. (2015). Electronic Word of Mouth on Instagram: Customers' Engagements with Brands in Different Sectors. International Journal of Management, Accounting \& Economics, 2(12), 1435-1444.

Friedman, H.; \& Friedman, L. (1979). Endorser Effectiveness by Product Type. Journal of Advertising Research. 19 (October/November), 63-71.

Gildin, S. (2003). Understanding the Power of Word of Mouth. Revista de Administração Mackenzie. 4(1), 91-106.

Han, B.O. \& Windsor, J. (2011). Users' willingness to pay on social network sites. Journal of Computer Information Systems, 51(4), 31-40.

Hennig-Thurau, T., Gwinner, P., Walsh, G., \& Gremle, D. (2004). Electronic wordof-mouth via consumer-opinion platforms: What motivates consumers to articulate themselves on the Internet?. Journal of Interactive Marketing. 18(1), $38-52$.

Hoffman, D.L. \& Fodor, M. 2010. Can You Measure the ROI of Your Social Media Marketing? MIT Sloan Management Review, 52(1), 41-49.

Hung, K., \& Li, S. (2007). The influence of eWOM on virtual consumer communities: social capital, consumer learning, and behavioral outcomes. Journal of Advertising Research. 47(4), 485-495.

Jansen, Bernard; Zhang, Mimi; Sobel, Kate; \& Chowdury, Abdur (2009). Twitter Power: Tweets as Electronic Word of Mouth. Journal of the American Society for Information Science and Technology. 60(11), 2169-2188.

Jin, S., \& Phua, J. (2014). Following celebrities' tweets about brands: The impact of twitter-based electronic word-of-mouth on consumers' source credibility perception, buying intention, and social identification with celebrities. Journal of Advertising. 43(2), 181. 
Kamins, M. A., Brand, M. J., Hoeke, S. A., \& Moe, J. C. (1989). Two-Sided Versus One-Sided Celebrity Endorsements: The Impact on Advertising Effectiveness and Credibility. Journal of Advertising. 18(2), 4-10.

Kelman, Herbert (1961). Processes of Opinion Change. Public Opinion Quarterly. 25 (1), 57-78.

Kim, A., \& Ko, E. (2012). Do social media marketing activities enhance customer equity?. An empirical study of luxury fashion brand. Journal of Business Research. 65, 1480-1486.

Kozinets, R. V., de Valck, K., Wojnicki, A. C., \& Wilner, S. J. (2010). Networked Narratives: Understanding Word-of-Mouth Marketing in Online Communities. Journal of Marketing, 74(2), 71-89.

Lee, M., \& Youn, S. (2009). Electronic word of mouth (eWOM): How eWOM platforms influence consumer product judgement. International Journal of Advertising. 28(3), 473.-499.

Lee, J., Park, D. H., \& Han, I. (2008). The effect of negative online consumer reviews on product attitude: an information processing view. Electronic Commerce Research and Applications, 7(3), 341-352.

Lee, M., Rodgers, S., \& Kim, M. (2009). Effects of valence and extremity of eWOM on attitude toward the brand and website. Journal of Current Issues \& Research in Advertising. 31(2), 1-11

Lin, Jhih-Syuan \& Pena, Jorge (2011). Are You Following Me? A Content Analysis of TV Networks' Brand Communication on Twitter. Journal of Interactive Advertising. 12 (1), 17-29.

Liu, M. T., Huang, Y. Y., \& Minghua, F. (2007). Relations among attractiveness of endorsers, match-up, and purchase intention in sport marketing in China. Journal of Consumer Marketing, 24(6), 358-365.

López, M., \& Sicilia, M. (2014). eWOM as Source of Influence: The Impact of Participation in eWOM and Perceived Source Trustworthiness on Decision Making. Journal of Interactive Advertising. 14(2), 86-97.

Marwick, A. \& Boyd, D. (2011). To See and Be Seen: Celebrity Practice on Twitter. Convergence: The International Journal of Research into New Media Technologies. 17(2), 139-158.

McKinsey (2010). A new way to measure word-of-mouth marketing. http://www.mckinsey.com/business-functions/marketing-and-sales/ourinsights/a-new-way-to-measure-word-of-mouth-marketing

Nambisan, S. (2002). Designing virtual customer environments for new product development: toward a theory. Academy of Management Review. 27(3), 392413.

Naylor, R.W., Lamberton, C.P. \& West, P.M. 2012. Beyond the 'Like' Button: The Impact of Mere Virtual Presence on Brand Evaluations and Purchase Intentions in Social Media Settings. Journal of Marketing, 76(6), 105-120.

Ohanian, R. (1991). The impact of celebrity spokespersons' perceived image on consumers' intention to purchase. Journal of Advertising Research. 31, 46-54.

Park, D.H., Kim, S. (2009). The effects of consumer knowledge on message processing of electronic word-of-mouth via online consumer reviews. Electron. Commerce Res. Appl. 7(4), 399-410.

Patra, S., \& Datta, S. K. (2012). Celebrity selection and role of celebrities in creating brand awareness and brand preference-a literature review. Journal of Marketing and Communication. 8: 48-57. 
Pfeffer, J., Zorbach, T., Carley, K.M. (2014). Understanding online firestorms: negative word-of-mouth dynamics in social media networks. Journal of Marketing Communications. 20, 117-128.

Phua, J., Jin, S. \& Kim, J. (2017). Gratifications of using Facebook, Twitter, Instagram, or Snapchat to follow brands: The moderating effect of social comparison, trust, tie strength, and network homophily on brand identification, brand engagement, brand commitment, and membership intention. Telematics and Informatics. 34(1), 412-424.

Senecal, S., \& Nantel, J. (2004). The influence of online product recommendations on consumers' online choices. Journal of Retailing. 80, 159-169.

Sun, T., Youn, S., Wu, G. \& Kuntaraporn, M. (2006). Online Word of Mouth: an Exploration of its Antecedents and Consequences. Journal of ComputerMediated Communication. 1(11), 1104-1127.

Till, B. (1998). Using celebrity endorsers effectively: lessons from associative learning. Journal of Product and Brand Management. 7(5), 400-409.

Xia, L., \& Bechwati, N. (2008). Word of Mouse: the Role of Cognitive Personalization in Online Consumer Reviews. Journal of Interactive Advertising. 9(1), 108-128.

Yan, Q., Wu, S., Wang, L., Wu, P., Chen, H., \& Wei, G. (2016). E-WOM from ecommerce websites and social media: Which will consumers adopt?. Electronic Commerce Research and Applications. 17, 1762-1773.

Jalilvand, M. R., Esfahani, S. S., \& Samiei, N. (2011). Electronic word-of-mouth: Challenges and opportunities. Procedia Computer Science, 3, 42-46. 